\title{
Long-Term Outcomes of Tamoxifen Citrate Therapy and Histo- and Immunopathological Properties in Riedel Thyroiditis
}

\author{
Asena Gökçay Canpolat ${ }^{a} \quad$ Murat Cinel $^{a}$ Serpil Dizbay Sak ${ }^{b}$ Işılay Taşkaldıran ${ }^{c}$ \\ Hakan Korkmaz $^{d}$ Özgür Demira Reyhan Ersoy ${ }^{\mathrm{e}}$ Selçuk Dağdelen ${ }^{f}$ \\ Dilek Berker $^{g} \quad$ Klara Dalvah $^{\text {h }}$ Adile Begüm Bahçecioğlu Mutlua
}

Murat Faik Erdoğana

aDepartment of Endocrinology and Metabolism, School of Medicine, Ankara University, Ankara, Turkey; ${ }^{b}$ Department of Pathology, School of Medicine, Ankara University, Ankara, Turkey; 'Department of Endocrinology and Metabolism, Ankara Training and Research Hospital, Ankara, Turkey; ${ }^{\mathrm{d} D e p a r t m e n t}$ of Endocrinology and

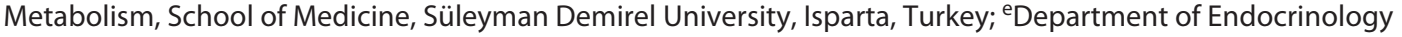
and Metabolism, School of Medicine, Yıldırım Beyazıt University, Ankara, Turkey; fDepartment of Endocrinology and Metabolism, School of Medicine, Hacettepe University, Ankara, Turkey; ${ }^{9}$ Department of Endocrinology and Metabolism, Ankara City Hospital, University of Health Sciences, Ankara, Turkey; hepartment of Haematology, School of Medicine, Ankara University, Ankara, Turkey

\section{Keywords}

Riedel thyroiditis · Immunoglobulin G4-related disease · Intercellular adhesion molecule-1 1 Transforming growth factor beta $\cdot$ Tamoxifen citrate $\cdot$ Plasmablast

\begin{abstract}
Background: Riedel thyroiditis (RT) is a rare form of thyroiditis; thus, data about the disease course and treatment options are limited. Therefore, we aimed to assess the clinical, serological, radiological, and histopathological features, as well as short- and long-term follow-up of RT patients under glucocorticoid (GC) and tamoxifen citrate (TMX). Parameters related to lgG4-related diseases (IgG4-RD) were also investigated. Methods: Eight patients with RT diagnosed between 2000 and 2019 were enrolled. Data were collected in a retrospective and prospective manner. The diagnosis was confirmed with histopathological features in all patients. Results of the treatment with GCs on short- to mid-term, followed by TMX in the long term, were evaluated. Results: The mean age at diagnosis was $40.5 \pm 6.8$ years; female predominance
\end{abstract}

was observed (F/M:7/1). Parameters related to IgG4-RD, like increase in IgG4 serum levels, total plasmablast counts, and IgG4+ plasmablasts, were negative in most of our patients in both active and inactive states of the disease. Likewise, an increased ratio of $\mathrm{lgG} 4 / \mathrm{lgG}$-positive plasma cells $>40 \%$ could only be observed in 2 cases. GCs followed by TMX were given to the patients with an over-all median follow-up time of 67 (8-216) months. All the patients considerably improved clinically and had a reduction in the size of the mass lesion on GCs, followed by TMX therapy. None of the patients had a recurrence under TMX therapy for a median period of 18.5 (7-96) months. Conclusion: Even though RT is suggested to be a member of IgG4-RD, serologic or histological evidence of lgG4 elevation or positivity is only useful for diagnosis and follow-up of RT. The diagnosis should be based on clinical and radiological evidence and confirmed by histopathology. GCs are effective for initial treatment, and TMX is a successful and safe therapeutic option for long-term maintenance therapy.
(C) 2020 European Thyroid Association Published by S. Karger AG, Basel 


\section{Introduction}

Immunoglobulin G4-related disease (IgG4-RD) is characterized by an immune-mediated fibroinflammatory process that can affect various organs [1]. Riedel thyroiditis (RT) is a rare form of thyroiditis, which may also occur as part of IgG4-RD. It is a fibroinflammatory involvement of the thyroid extending to surrounding tissues. Well-defined diagnostic criteria of RT are follows: (i) fibroinflammatory process involving all or a portion of the thyroid, (ii) evidence of extension beyond the gland, (iii) absence of giant cells, lymphoid follicles, oncocytes, or granulomas, (iv) evidence of occlusive phlebitis, and (v) absence of a neoplasm [2]. Its incidence was estimated to be 1.06 cases per 100,000 population (female/male: $3-4$ and frequent at ages of $30-50$ years), the operative incidence is $0.06 \%$ [3-5]. Heritability of RT is unclear [4].

Despite significant advancement for recognition and management of the IgG4-RD, the diagnosis and treatment of RT is still challenging because of the rarity of the disease. Although there are various case-based reports in the literature, little is known about the clinicopathological features and long-term follow-up of these patients. Therefore, we aimed to assess the clinicopathological and serological features of this rare entity and to find out the long-term therapeutic effects of tamoxifen citrate (TMX) in 8 patients with RT.

\section{Methods}

\section{Study Population}

Eight patients having clinical and radiological findings consistent with RT between 2000 and 2019 were enrolled. Three of them had been referred from other collaborative centers, and the remaining 5 of them were diagnosed and treated in our institution. Ankara University funded the Project (Project number 15B0230008).

Although RT may present as 1 component of IgG4-RD, the diagnosis of RT in our patients was mainly based on the histopathological diagnostic criteria given above, that is, confirmation of inflammation, destruction of parenchyma, and extension into surrounding tissues in the presence of consistent clinical/radiological findings $[6,7]$. In contrast, a definite diagnosis of IgG4-RD was made when all 3 criteria (clinical, serological, and histopathological) were met, that is, the presence of either a localized or diffuse mass or swelling involving 1 or more organs, the existence of elevated serum IgG4 level of $>135 \mathrm{mg} / \mathrm{dL}$, tissue infiltration with dense lymphoplasmacytic infiltrate and fibrosis, 10 or more IgG4positive cells per high-power field (HPF), and a ratio of IgG4/IgGpositive plasma cells of $>40 \%$ [8].

Riedel Thyroiditis and Tamoxifen

Treatment
Clinical Assessment

The complaints and findings that could be relevant with RT and IgG4-RD, such as malaise, weight loss, dyspnea, chest pain, neck tightness, arthralgias, proptosis, enlargement of the submandibular glands, xerophthalmia, abdominal pain, diarrhea, or jaundice were evaluated.

\section{Serologic Assessment}

Fasting morning blood samples were obtained from each patient for the measurement of routine complete blood count, biochemistry, erythrocyte sedimentation rate (ESR), serum C-reactive protein (CRP), thyroid function tests, thyroid antibodies, and parathormone levels. All serological tests were obtained for patients at the time of the recruitment. Autoimmune markers such as an anti-nuclear antibody (ANA), anti-neutrophil cytoplasmic antibody, extracted nuclear antigen, anti-smooth muscle antibody, anti-mitochondrial antibody, anti-liver kidney microsomal enzyme, complement levels, and total IgG and IgG4 levels in sera were analyzed. Serum fibrosis markers such as Intercellular Adhesion Molecule-1 (Boster ${ }^{\circledR}$ Picokine ELISA Human-ICAM-1) and Transforming Growth Factor beta (Boster ${ }^{\circledR}$ Picokine ELISA TGF- $\beta$ ) serum levels were also analyzed. The intra- and inter-assay coefficients of variation for TGF- $\beta$ were 7.1 and $8.3 \%$, and for ICAM-1 they were 4.7 and $4.9 \%$, respectively.

Radiological Assessment

CT of neck, chest, and abdomen was used to reveal any other accompanying silent IgG4-RD. Neck ultrasonography was performed in each visit of the patients by the same experienced endocrinologist (MFE) by using a Logiq S6 ultrasound system $\left(\mathrm{GE}^{\circledR}\right.$ Healthcare, Milwaukee, WI, USA) and a $10-13 \mathrm{MHz}$ broadband linear probe. The volume of the thyroid lobes was calculated according to the ellipsoid formula: lobe volume $(\mathrm{mL})=\operatorname{depth}(\mathrm{cm})$ $\times$ width $(\mathrm{cm}) \times$ length $(\mathrm{cm}) \times \pi / 6[9]$.

Pathological Assessment

Archived tissue samples from previous biopsies of all patients were re-examined. Histological examination was carried out by a single pathologist (SDS) on formalin-fixed, paraffin-embedded blocks, and hematoxylin and eosin stained sections. For all cases, IgG4 (Abcam ${ }^{\circledR}$, Anti-IgG4 antibody [EP4420]), IgG, CD20, and CD3 immunohistochemical stains were performed. For immunohistopathological evaluation of IgG4 and IgG, the whole section was screened in medium power for hot spots, and positive cells were counted in 3 HPFs in hot spots $\left(\times 400\right.$ Olympus ${ }^{\circledR}$ BX50). Besides, Elastic Van Gieson, cytokeratin (AE1/AE3), TTF1, thyroglobulin, PAX8, desmin, p63, CD34, CD31, ICAM-1 antibody (Abcam ${ }^{\circledR}$, Anti-ICAM-1 antibody [EPR4776]), and TGF- $\beta$ antibody $\left(\right.$ Abcam ${ }^{\circledR}$, Anti-TGF- $\beta$ antibody [TGF- $\left.\left.\beta 17\right]\right)$ stains were performed.

\section{Flow Cytometric Study for Plasmablasts}

The ratio of plasmablast was detected in EDTA-anticoagulated peripheral blood samples, which were incubated with $\mathrm{AB} \mathrm{Rh}+\mathrm{se}$ rum for 10 min to block Fc receptors. Upon a washing step, 5-7 $\mu \mathrm{L}$ of each monoclonal antibody was added to the tube and incubated for $20 \mathrm{~min}$. After a lysing step (10 min with $1 \mathrm{~mL}$ Optilyse/tube, Beckman Coulter $\left.{ }^{\circledR}\right)$, the samples were washed twice using PBS containing 5\% FCS (300 g) and resuspended within $0.5 \mathrm{~mL}$ PBS. 
Upon the daily control of the system, data collection $\left(10^{6}\right.$ cells/ tube) was performed within $1 \mathrm{~h}$ using a 3 Laser 10 color flow cytometer, Navios (Beckman Coulter ${ }^{\circledR}$, Miami, FL, USA). Collected data were analyzed using the Kaluza Analysis 2.1 software (Beckman Coulter ${ }^{\circledR}$, Miami, FL, USA). Plasmablasts were detected within CD45+ cells (CD38+, CD138+, CD19+, CD20-, CD27+, and $\mathrm{CD} 10+)$, and the IgG4 expression of plasmablasts was also detected.

Therapeutic Approach

Glucocorticoids (GCs) had been given routinely to all patients at the beginning of the therapy. In the case of life-threatening severe dyspnea, the prednisolone was administered parenterally $2-3$ $\mathrm{mg} / \mathrm{kg} /$ day for 2-7 days according to the clinical response. It was replaced with an oral route and continued with $0.8-1 \mathrm{mg} / \mathrm{kg} / \mathrm{day}$. Patients who do not need an initial parenteral steroid therapy received steroid $0.8-1 \mathrm{mg} / \mathrm{kg} /$ day orally for $4-8$ weeks, followed by dose titration and cessation of the treatment in 6-12 months according to clinical response.

TMX $10-20 \mathrm{mg} /$ day was given to patients for maintenance therapy 1-3 months before the cessation of the GC treatment. Thus, there was a timeframe of 1-3 months of dual therapy before the cessation of GC therapy. Azathioprine and colchicine were added to 1 patient who had concomitant polyserositis.

Response to therapy has been assessed by using imaging modalities (both ultrasonography and CT of the affected region) and laboratory results every 3-6 months of treatment. The response to therapy was determined as follows: alleviation of the complaints due to the mass effect, reduction of the volume of the mass lesion (at least 25\%), and decrease in inflammation markers.

\section{Statistical Analysis}

Numerical variables with a normal distribution were presented as the mean \pm standard deviation, numerical variables with a skewed distribution were presented as the median (minimum and maximum), and categorical variables were presented as numbers and percentages. The mean thyroid volumes at the beginning of the treatment and final condition were compared with paired samples $t$ test. Statistical analyses were performed using SPSS statistical software (IBM Corp. Released in 2015. IBM SPSS Statistics for Windows, Version 23.0; IBM Corp., Armonk, NY, USA). $p$ value $<0.05$ was determined as significant.

\section{Results}

\section{Clinical Features of $R T$}

The baseline demographic and clinical data of all patients were represented in Table 1 . Half of the patients were in the active state $(n: 4)$, whereas 4 of them $(n: 4)$ were in an inactive state under treatment at the time of the recruitment. The mean age at diagnosis was $40.5 \pm 6.8$ years. The mean age of the patients was $45.5 \pm 7$ years with a female predominance (F/M: 7/1). The most common symptom and signs were dyspnea and neck mass. Besides, 1 patient was presented with dyspnea due to pleuro-pericardial effusion [10] and 1 with hypoparathyroidism (re- solved after treatment). One patient had a concurrent history of malignancy (breast cancer) with no history of radiation therapy. Behçet's disease was accompanying in 1 patient. None of the patients had clinical manifestations for IgG4-RD.

\section{Laboratory Tests}

The mean ESR and median CRP, IgG, and IgG4 levels of the patients at the time of recruitment were given in Table 2. There were no significant differences between active and inactive patients at the time of recruitment.

Two of the patients had positive anti-TPO, anti-Tg, and TSH receptor antibodies, and they were hypothyroid for several years before the diagnosis of RT. However, none of them had a history of Graves' disease. The median TSH level was 2.4 (1.4-26) $\mathrm{mIU} / \mathrm{L}$ (reference range [0.35-5]), the mean free thyroxine was $14 \pm 2.6 \mathrm{pmol} / \mathrm{L}$ (reference range 7-18), and the mean free tri-iodothyronine was $3.9 \pm 0.57$ (reference range 4-7.5). Five of the antibody-negative patients were euthyroid at the recruitment but became hypothyroid during the follow-up. One patient was euthyroid at the time of diagnosis and remained so during the follow-up. The median time elapsed from RT diagnosis, and onset of hypothyroidism was 4.5 (0-24) months.

None of the patients had autoimmune markers such as ANA. Serum complement levels (C3, C4) were also found within normal limits for both active and inactive patients. Median TGF- $\beta$ and mean ICAM-1 levels were 668 (212$22,960) \mathrm{pg} / \mathrm{mL}$ and $17,075 \pm 5,182 \mathrm{pg} / \mathrm{mL}$, respectively (Table 2). These values were within normal ranges, determined according to the mean +2 SD of the normal control group (i.e., $12,036 \pm 11,512 \mathrm{pg} / \mathrm{mL}$ for mean TGF- $\beta$ and $13,786 \pm 12,864 \mathrm{pg} / \mathrm{mL}$ for mean ICAM-1).

\section{Imaging Tests}

The ultrasonographic evaluation revealed mainly hypoechogenic and large heterogeneous thyroid tissue extending beneath the incisura jugularis, surrounding adjacent tissues, including pathognomonic carotid arterial encasement in all patients, which was confirmed by neck CT. Four patients had mediastinal masses extending down to the level of arcus aorta. There was a significant decrease in the final thyroid volumes of the group after treatment when compared to the recruitment $(30.3 \pm 17$ vs. $11.6 \pm 7.9, p: 0.014)$. Interestingly, we found incidental and asymptomatic parotid gland enlargement in 1 patient with paranasal CT. 


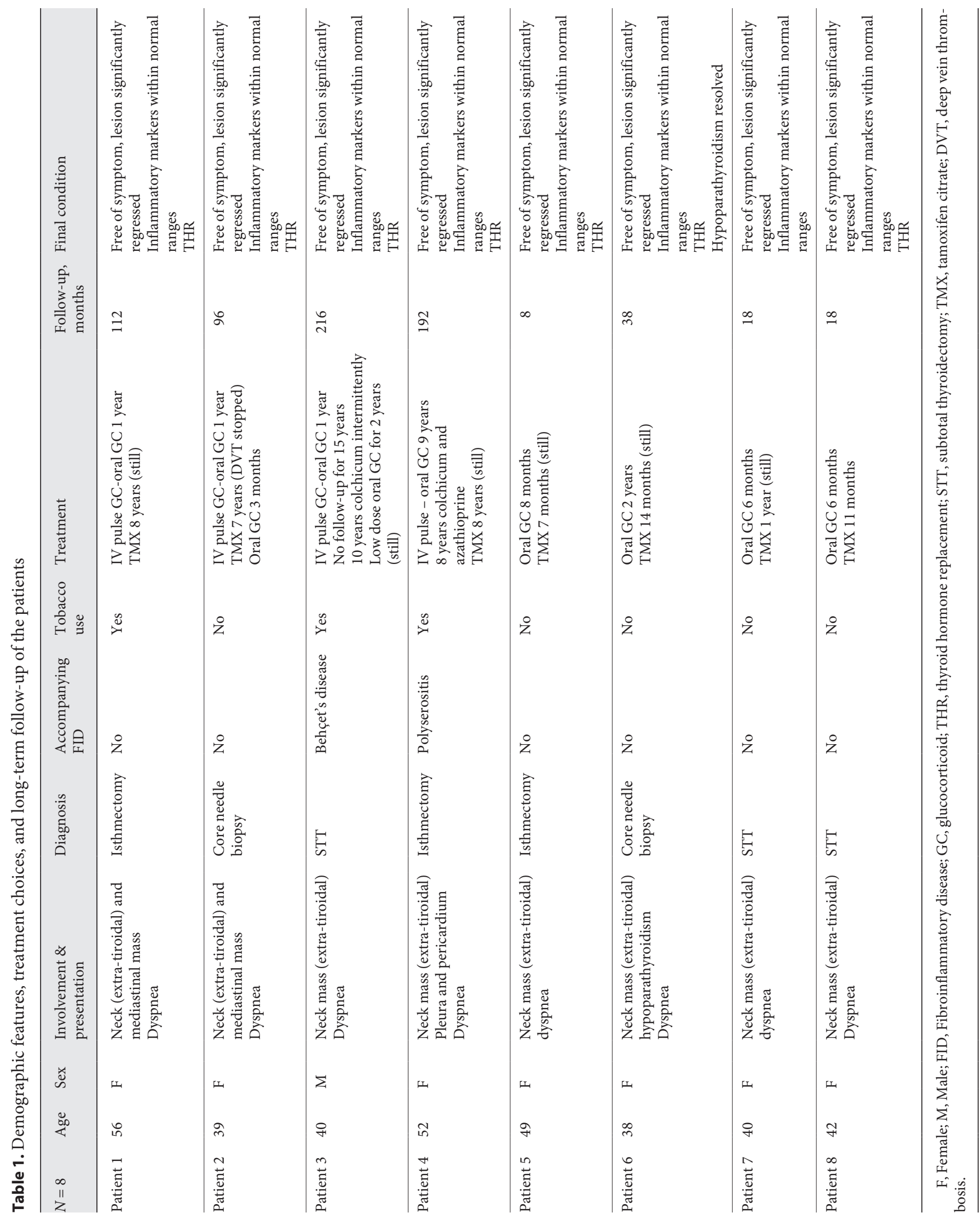


Table 2. Laboratory features of the patients with RT at the time of recruitment

\begin{tabular}{|c|c|c|c|c|c|c|c|c|c|c|}
\hline Patient & $\begin{array}{l}\text { TSH levels } \\
\mathrm{mIU} / \mathrm{L}\end{array}$ & Thyroid antibody & $\begin{array}{l}\text { Autoimmune } \\
\text { markers* }\end{array}$ & $\begin{array}{l}\text { Disease } \\
\text { activity }\end{array}$ & $\begin{array}{l}\text { ESR } \\
(0-25 \mathrm{~mm} / \mathrm{h})\end{array}$ & $\begin{array}{l}\mathrm{CRP} \\
(0-5 \mathrm{mg} / \mathrm{L})\end{array}$ & $\begin{array}{l}\text { Serum IgG4 } \\
(0.03-0.8 \mathrm{~g} / \mathrm{L})\end{array}$ & $\begin{array}{l}\text { Serum IgG } \\
(7.51-15.6 \mathrm{~g} / \mathrm{L})\end{array}$ & $\begin{array}{l}\text { Serum } \\
\text { TGF- } \beta \text {, } \\
\text { pg/mL }\end{array}$ & $\begin{array}{l}\text { Serum } \\
\text { ICAM-1, }{ }^{* *} \\
\mathrm{pg} / \mathrm{mL}\end{array}$ \\
\hline Patient 2 & 1.4 & Negative & Negative & Active & 30 & 13.8 & 0.27 & 12.5 & 22,960 & 9,546 \\
\hline Patient 3 & 9.6 & $\begin{array}{l}\text { Anti-TPO, anti-Tg, } \\
\text { and TRAB positive }\end{array}$ & ANA positivity & Active & 62 & 64.0 & 0.14 & 14.9 & 300 & 20,564 \\
\hline Patient 4 & 1.9 & Negative & Negative & Inactive & 31 & 27.0 & 0.17 & 13.7 & 18,950 & 14,380 \\
\hline Patient 5 & 26.0 & $\begin{array}{l}\text { Anti-TPO, anti-Tg, } \\
\text { and TRAB positive }\end{array}$ & Negative & Inactive & 3 & 1.0 & 0.3 & 9.5 & 556 & 21,200 \\
\hline Patient 6 & 6.3 & Negative & Negative & Active & 19 & 14.9 & 0.39 & 12.6 & 780 & 16,850 \\
\hline
\end{tabular}

TSH, thyroid stimulating hormone; ESR, erythrocyte sedimentation rate; CRP, C-reactive protein; IgG4, immunoglobulin G; TGF- $\beta$, transforming growth factor beta; ICAM-1, Intercellular adhesion molecule; Anti-Tpo, anti-thyroid peroxidase; Anti-Tg, anti-tiroglubuline; TRAB, thyroid stimulating hormone receptor antibody; RT, Riedel thyroiditis; ANA, anti-nuclear antibody; IgG4, immunoglobulin G4. * Autoimmune markers: ANA, Anti-ds DNA, ANCA, ENA, AMA, ASMA, and LKM. ** The measurement of both TGF- $\beta$ and ICAM-1 levels in sera of all of the patients revealed values lower than the upper limit of the normal ranges, determined as the mean $+2 \mathrm{SD}$ of the normal control group.

Table 3. Histopathological characteristics of 8 cases with RT

\begin{tabular}{|c|c|c|c|c|c|c|c|c|c|}
\hline Patient 2 & 1 (Tru-Cut) & na & na & Mild & - & $3-7(5)$ & $14-26(20)$ & 25.0 & $\mathrm{pRT}$ \\
\hline Patient 3 & 2 & + & + & Moderate & + & $6-15(10)$ & $58-70(65)$ & 15.7 & RT \\
\hline Patient 5 & 1 (Tru-Cut) & - & + & Mild & + & $7-12(10)$ & $10-24(17)$ & 58.8 & RT \\
\hline Patient 6 & 2 & - & + & Mild & - & $1-2(1)$ & $3-6(4)$ & 30.2 & $\mathrm{pRT}$ \\
\hline Patient 7 & 3 & - & + & Moderate & + & $5-8(7)$ & $75-94(84)$ & 7.8 & RT \\
\hline Patient 8 & 3 & - & + & Moderate & + & $1-15(6)$ & $17-25(22)$ & 25.4 & RT \\
\hline
\end{tabular}

FI, Fibrosis \& inflammation; HPF, high-power field; na, not applicable; RT, consistent with Riedel thyroiditis, pRT, probable Riedel thyroiditis.

\section{Histopathologic Results}

Paraffin blocks were available for examination in all cases (Table 3). Most were surgical specimens from thyroid surgery $(n=6)$, except for 1 Tru-Cut biopsy from the thyroid and 1 Tru-Cut biopsy from the mediastinal mass. On histological examination, scar-like fibrosis and mildto-moderate lymphoplasmacytic infiltration were pres- ent in all. Eosinophils were never a prominent contributor to inflammation; however, they constituted an easily identifiable component of the inflammation except for 2 Tru-Cut materials. Extension of the fibroinflammatory process beyond the thyroid gland was a consistent finding that was easily identified in 7 cases (Fig. 1a, b). Occlusive phlebitis was observed in 6 of our 8 cases (Fig. 1c). Non- 
occlusive phlebitis and occlusive changes in the arteries were also noted. Residual thyroid tissue was observed in only 2 cases.

By using the criteria as mentioned above [6,7], 6 cases were classified as histologically consistent with RT, and 2 cases were diagnosed as probable RT. One of these probable RT cases was a thyroid Tru-Cut that did not show occlusive phlebitis. In one further case, in which only a mediastinal Tru-Cut biopsy was available, a definitive diagnosis could not be reached histopathologically. However, this case was also consistent with RT clinically and radiologically, like our 7 other cases.

Mild-to-moderate inflammation consisting of generally dispersed CD3-positive T cells and CD20-positive B cells forming small groups was observed in all cases. The mean counts of IgG4-positive cells were in a range of 1.3$56.3 / \mathrm{HPF}$ in our cases, and the IgG4/IgG ratio was between 7.8 and 58.8\% (Table 3). IgG4- and IgG-positive cells showed a tendency to accumulate around blood vessels (Fig. 1d). An increased ratio of IgG4/IgG-positive plasma cells $>40 \%$, which is the histological hallmark of IgG4-RD, was observed in only 2 cases (Table 3). ICAM1 stained endothelial and inflammatory cells; in some cases, fibroblasts were also stained. For TGF- $\beta$, staining of inflammatory cells and fibroblasts and also some interstitial staining were observed.

\section{Flow-Cytometric Results}

The patients did not have elevated total plasmablast counts, and none of them had IgG4-positive plasmablasts in peripheral blood analysis in either active or inactive states of RT.

\section{Treatment and Long-Term Outcomes}

Median follow-up time was 67 (8-216) months. Debulking surgery/isthmectomy had been performed for diagnosis and relieving the obstruction in 6 patients and Tru-Cut biopsy in 2 patients (Table 1 ). Among study participants, 7 of the patients required thyroid hormone replacement (Table 2) in the long term. One patient had hypoparathyroidism at her first admission, but recovery with normal serum calcium and parathyroid hormone levels was observed after treatment.

The whole group received prednisolone as initial therapy (detailed information concerning route, dose, and duration of the treatment was given above), and 4 cases with severe dyspnea were treated with high doses of intravenous steroids. One patient who had used GCs for an extended period (108 months) had concomitant polyserositis and received additional azathioprine and colchi-
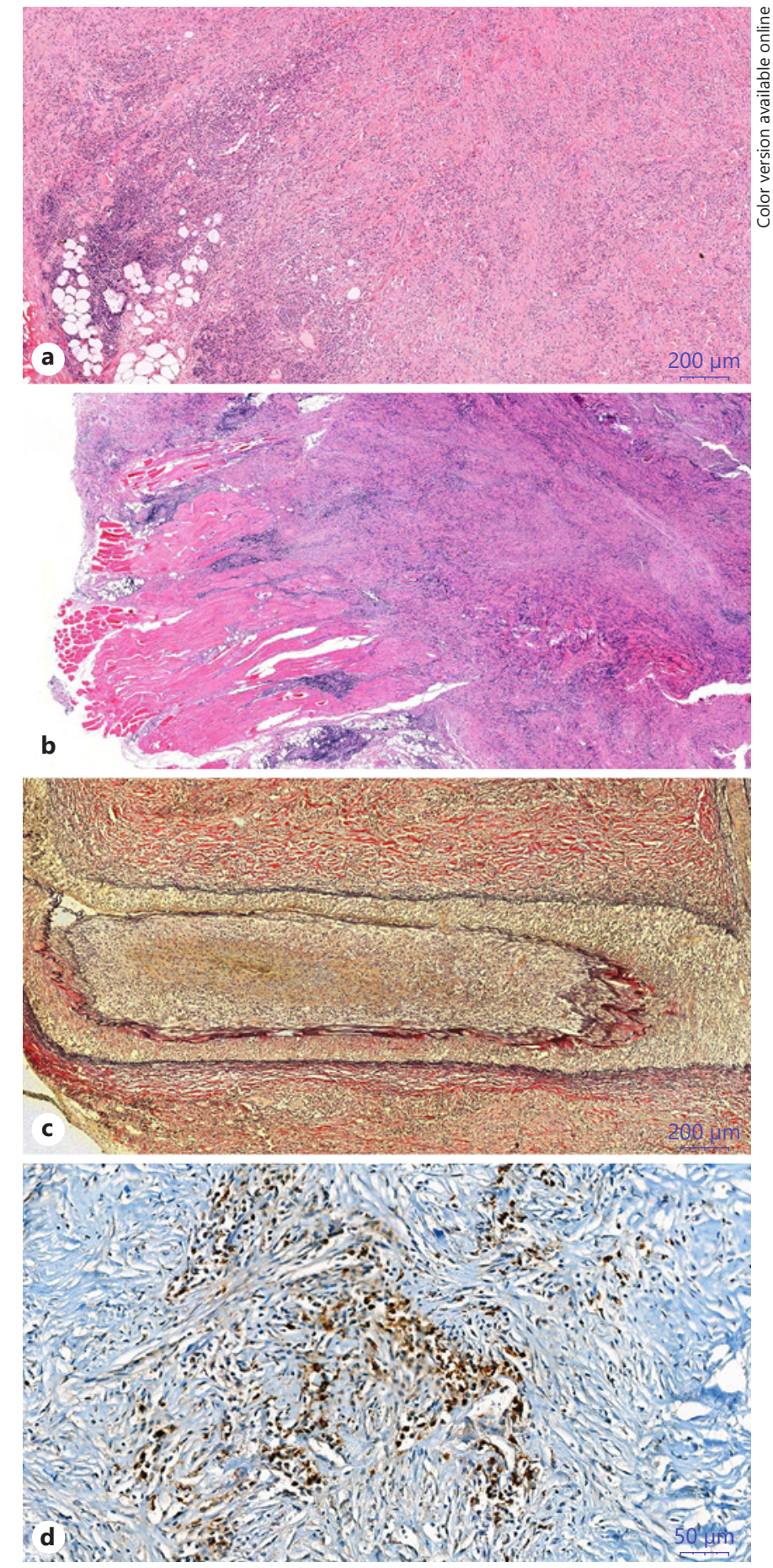

Fig. 1. Fibroinflammatory spread to the adjacent structures. Fibroinflammatory process involving adipose tissue (HE, digital image, $\times 6.0)(\mathbf{a})$, fibroinflammatory process involving striated muscle of the neck $(\mathrm{HE}$, digital image, $\times 2.6)(\mathbf{b})$, fibroinflammatory process obliterating a vascular structure (EVG, digital image, ×6.2) (c). d IgG4-positive cells accumulating around blood vessels (HE, digital image, $\times 23.5$ ). HE, hematoxylin and eosin; EVG, Elastic Van Gieson; IgG4, immunoglobulin G4. 
cine due to severe effusions comprising pleura and pericardium. Oral prednisone was started $0.8-1 \mathrm{mg} / \mathrm{kg}$ per day for 4-8 weeks followed by dose reduction and cessation of the therapy in the median $13.5(6-108)$ months with a median dose of 13.8 (9.3-34) $\mathrm{mg} /$ day according to improvement in clinical status (Table 1). GC cessation was managed appropriately in all steroid receiving groups.

TMX (10-20 mg/day) for a median period of 18.5 (796) months was given to all patients for maintenance therapy, except 1 patient who had concomitant Behçet's disease and a history of deep vein thrombosis (DVT). Accordingly, 1 female patient had DVT during TMX therapy with the cessation of the drug after 84 months of treatment. No other adverse effects were reported related to TMX, and it was well tolerated.

After a median follow-up of 67 (8-216) months, improvement and stabilization of the disease were achieved in all patients. No disease, surgical, or drug-related morbidity was observed. In general, isolated RT is a disease that responds well to the treatment. The patients are in good health status without signs of progression of the disease with proper treatment, years after diagnosis.

\section{Discussion}

Due to the rarity of the disease, there are still no randomized clinical trials and standard treatment modalities for RT. We herein reported our long-term experience regarding clinical, radiological, and laboratory features, and the results of long-term therapy. Since some of the cases of RT are associated with IgG4-RD, we also conducted IgG4-related immunohistochemical, flow-cytometric, and serological analyses.

Serum IgG4 levels were reported to be raised with a sensitivity and specificity of 90 and $60 \%$ in IgG4-RD, respectively [11]. However, the positive predictive value of elevated serum levels was reported to be as weak as $10 \%$ [12]. Either in the active or inactive state of the disease, none of our patients had elevated serum IgG4 levels. Similarly, inflammatory markers (ESR and CRP) were also found to be unremarkable. In consistence with the previous reports, ANAs were negative, and complement serum levels were normal in all of our patients, indicating that they are only supportive measurements for follow-up.

In contrast with the literature, only 2 of our 8 patients had positive thyroid autoimmunity [4]. Everyone in the group except 1 patient had already had or developed hypothyroidism during the follow-up. The possible mechanism for deteriorating thyroid functions seems to be due to the ongoing fibroinflammatory process and surgical resections, rather than autoimmunity.

As mentioned before, TGF- $\beta$ is a crucial cytokine in proliferation, differentiation, and growth and a potent fibrogenic molecule that initiates and terminates tissue repair. Sustained production of TGF- $\beta$ and ICAM- 1 , which is a primary adhesion receptor for monocyte/macrophage attachment to endothelial cells, may have a potential role in mediating fibrogenesis [13]. ICAM-1 was also reported to initiate TGF- $\beta$ induction [14]. Thus, we conducted serologic and histopathologic analyses for these fibrosis markers to prove the ongoing fibrotic process in RT. However, the ICAM- 1 and TGF- $\beta$ levels were within normal limits.

Wallace et al. [9] first examined the utility of elevated circulating total and IgG4+ plasmablasts as biomarkers of diagnosis and disease activity in IgG4-RD. They also suggested that circulating plasmablasts might be elevated even in patients with normal serum IgG4 levels and may correlate with the disease activity [9]. Our findings were inconsistent with this literature although nearly half of the patients had active disease.

Even though RT is suggested to be included in the IgG4-RD spectrum [15], our findings are consistent with the perspective of Kakudo et al. [16], who suggested that RT does not entirely overlap with IgG4-related "thyroid" disease (IgG4-RTD). Another aspect that was claimed recently [13] is that the number of IgG4+ plasma cells also depends on the duration of the disease. They may be secondary to the autoimmune process acting as a counterregulatory mechanism against inflammation. Thus, IgG4+ cells may be found in recent-onset cases but may disappear later during the ongoing fibrotic process. Accordingly, 2 of our cases showed $>40 \%$ IgG4 positivity and were in the early active and untreated phase of the disease. Histopathologic diagnosis is mandatory for RT, but immunostaining for plasma cell subtypes could only be a supportive tool depending on the activity of the disease.

Pathogenesis of the disease has not yet been established completely; therefore, definite treatment guidelines are lacking. Since the disease course differs from most of the other forms of IgG4-RD, the treatment strategies towards RT should be different from IgG4-RD. Active RT with local compression may require surgical debulking/isthmectomy since thyroidectomy is usually associated with significant morbidities, and extensive surgery is inappropriate for most of the cases [4]. GCs followed by TMX are the drugs of choice for RT for the moment $[3,4,7,14,17-19]$. There are various reports for dosage starting from 15 to $100 \mathrm{mg}$ of prednisone per day. 
Maintaining the initial GC dosage $(0.8-1 \mathrm{mg} / \mathrm{kg} / \mathrm{day}$ prednisolone) for 2-4 weeks and tapering gradually upon clinical improvement is our clinical approach. The GC administration should be limited to 6-12 months after initiation [20]. Steroid-sparing agents are used in maintenance therapy to lower long-term GC toxicities and to increase the success rates of treatment compared to monotherapy with GCs. The optimal duration and doses of these agents for maintenance therapy have not been evaluated in detail. In our cases, $\mathrm{RT}$ responded well to GC and TMX, and rituximab can be saved for more aggressive and refractory disease $[21,22]$.

TMX can be the second agent after steroid therapy in RT. Few et al. [17] first reported the successful treatment with TMX in 4 cases with RT in 1996. The proposed mechanism is consequent inhibition of fibroblast proliferation and collagen production, probably through its detractive effect on the expression of TGF- $\beta$ [4]. TMX at $10-20 \mathrm{mg}$ doses has been used successfully either in combination with GC therapy or as monotherapy with no severe side effects on the long-term use [3, 19, 23, 24]. Rare adverse effects are related to its estrogenic activity, including endometrial cancer and DVT, supported by large, randomized clinical trials. Thus, it should be used with caution in patients with predisposing diseases and known risk factors for DVT [25].

There were scarce data with TMX in RT, including few case reports and small case series. The most extensive case series of Mayo Clinic experience, including 21 patients, revealed that 6 patients received TMX, 4 of them also received GC, and 3 of the patients had a progression of disease despite 6 months of TMX. In our study, the majority of the patients $(n: 7)$ were treated with TMX monotherapy after GCs. None of the patients had a relapse or progression of the disease. Only 1 female patient who had predisposing factors for DVT (i.e., smoking and obesity) had DVT after 7 years of treatment.

To the best of our knowledge, our study is the first with the extended follow-up, suggesting that TMX may be an efficient, safe, and well-tolerated long-term treatment option for RT after cessation of GC. However, there is no obvious evidence for the duration of maintenance therapy in the long term.

\section{Conclusion}

Diagnosis of RT is based on clinical, radiological, and histopathological evaluations in experienced centers. Serologic investigations can be used as supportive measures

but are not diagnostic. GCs are the first-line treatment for most of the cases. TMX is a safe and effective therapeutic option after the cessation of GCs on the long-term followup.

\section{Acknowledgement}

We would like to thank Ankara University Scientific Research Projects Unit, who funded the project with the project number 15B0230008.

\section{Statement of Ethics}

The study was in accordance with the ethical standards of the institutional research committee of Ankara University (Decision number 02-75-15; 9 September 2015), and all subjects signed informed consent forms.

\section{Conflict of Interest Statement}

None of the authors have any potential conflicts of interest associated with this research.

\section{Funding Sources}

This research was supported by the Ankara University Scientific Research Projects Unit (Project number 15B0230008).

\section{Author Contributions} ship.

All the authors of the manuscript fulfill the criteria for author-

References

Eur Thyroid J 2021;10:248-256

DOI: $10.1159 / 000512017$
1 Lang D, Zwerina J, Pieringer H. IgG4-related disease: current challenges and future prospects. Ther Clin Risk Manag. 2016;12:189-99.

2 Takeshima K, Inaba $\mathrm{H}$, Ariyasu $\mathrm{H}$, Furukawa Y, Doi A, Nishi M, et al. Clinicopathological features of Riedel's thyroiditis associated with IgG4-related disease in Japan. Endocr J. 2015; 62(8):725-31.

3 Fatourechi MM, Hay ID, McIver B, Sebo TJ, Fatourechi V. Invasive fibrous thyroiditis (Riedel thyroiditis): the Mayo Clinic experience 1976-2008. Thyroid. 2011 Jul;21(7): 765-72.

4 Hennessey JV. Clinical review: Riedel's thyroiditis: a clinical review. J Clin Endocrinol Metab. 2011 Oct;96(10):3031-41.

5 Zakeri H, Kashi Z. Variable clinical presentations of Riedel's thyroiditis: report of two cases. Case Rep Med. 2011;2011:709264. 
6 Deshpande V, Zen Y, Chan JK, Yi EE, Sato Y, Yoshino T, et al. Consensus statement on the pathology of IgG4-related disease. Mod Pathol. 2012 Sep;25(9):1181-92.

7 Falhammar H, Juhlin CC, Barner C, Catrina SB, Karefylakis C, Calissendorff J. Riedel's thyroiditis: clinical presentation, treatment and outcomes. Endocrine. 2018 Apr;60(1): 185-92.

8 Islam AD, Selmi C, Datta-Mitra A, Sonu R, Chen M, Gershwin ME, et al. The changing faces of IgG4-related disease: clinical manifestations and pathogenesis. Autoimmun Rev. 2015 Oct;14(10):914-22.

9 Wallace ZS, Mattoo H, Carruthers M, Mahajan VS, Della Torre E, Lee H, et al. Plasmablasts as a biomarker for IgG4-related disease, independent of serum IgG4 concentrations. Ann Rheum Dis. 2015 Jan;74(1):190-5.

10 Erdogan MF, Anil C, Turkcapar N, Ozkaramanli D, Sak SD, Erdogan G. A case of Riedel's thyroiditis with pleural and pericardial effusions. Endocrine. 2009 Jun;35(3):297301.

11 Carruthers MN, Khosroshahi A, Augustin T, Deshpande V, Stone JH. The diagnostic utility of serum IgG4 concentrations in IgG4-related disease. Ann Rheum Dis. 2015 Jan;74(1): 14-8.
12 Ngwa TN, Law R, Murray D, Chari ST. Serum immunoglobulin G4 level is a poor predictor of immunoglobulin G4-related disease. Pancreas. 2014 Jul;43(5):704-7.

13 Rotondi M, Carbone A, Coperchini F, Fonte $\mathrm{R}$, Chiovato L. Diagnosis of endocrine disease: IgG4-related thyroid autoimmune disease. Eur J Endocrinol. 2019 May 1;180(5): R175-R83.

14 Bagnasco M, Passalacqua G, Pronzato C, Albano M, Torre G, Scordamaglia A. Fibrous invasive (Riedel's) thyroiditis with critical response to steroid treatment. J Endocrinol Invest. 1995 Apr;18(4):305-7.

15 Dahlgren M, Khosroshahi A, Nielsen GP, Deshpande V, Stone JH. Riedel's thyroiditis and multifocal fibrosclerosis are part of the IgG4-related systemic disease spectrum. Arthritis Care Res. 2010 Sep;62(9):1312-8.

16 Kakudo K, Li Y, Taniguchi E, Mori I, Ozaki T, Nishihara E, et al. IgG4-related disease of the thyroid glands. Endocr J. 2012;59(4):273-81.

17 Few J, Thompson NW, Angelos P, Simeone D, Giordano T, Reeve T. Riedel's thyroiditis: treatment with tamoxifen. Surgery. 1996 Dec; 120(6):993-8.

18 Vaidya B, Harris PE, Barrett P, Kendall-Taylor P. Corticosteroid therapy in Riedel's thyroiditis. Postgrad Med J. 1997 Dec;73(866): 817-9.

19 Pritchyk K, Newkirk K, Garlich P, Deeb Z. Tamoxifen therapy for Riedel's thyroiditis. Laryngoscope. 2004 Oct;114(10):1758-60.
20 Khosroshahi A, Wallace ZS, Crowe JL, Akamizu T, Azumi A, Carruthers MN, et al. International consensus guidance statement on the management and treatment of IgG4-related disease. Arthritis Rheumatol. 2015 Jul;67(7): 1688-99.

21 Soh SB, Pham A, O'Hehir RE, Cherk M, Topliss DJ. Novel use of rituximab in a case of Riedel's thyroiditis refractory to glucocorticoids and tamoxifen. J Clin Endocrinol Metab. 2013 Sep;98(9):3543-9.

22 Hunt L, Harrison B, Bull M, Stephenson T, Allahabadia A. Rituximab: a novel treatment for refractory Riedel's thyroiditis. Endocrinol Diabetes Metab Case Rep. 2018;2018(1):170132.

23 Jung YJ, Schaub CR, Rhodes R, Rich FA, Muehlenbein SJ. A case of Riedel's thyroiditis treated with tamoxifen: another successful outcome. Endocr Pract. 2004 Nov-Dec;10(6): 483-6.

24 Levy JM, Hasney CP, Friedlander PL, Kandil E, Occhipinti EA, Kahn MJ. Combined mycophenolate mofetil and prednisone therapy in tamoxifen- and prednisone-resistant Reidel's thyroiditis. Thyroid. 2010 Jan;20(1):105-7.

25 Meier CR, Jick H. Tamoxifen and risk of idiopathic venous thromboembolism. Br J Clin Pharmacol. 1998 Jun;45(6):608-12. 